\title{
A Robust Mathematical Model for Sustainable and Resilient Supply Chain Network Design: Preparing a Supply Chain to Deal with Disruptions
}

\author{
Zahra Sadeghi, Omid Boyer (D), Shila Sharifzadeh $(D$, and Nadia Saeidi $(1)$ \\ Department of Industrial Engineering, Najafabad Branch, Islamic Azad University, Najafabad, Iran \\ Correspondence should be addressed to Omid Boyer; omidboyer@gmail.com
}

Received 5 March 2021; Revised 24 May 2021; Accepted 20 September 2021; Published 27 October 2021

Academic Editor: Lei Xie

Copyright ( 2021 Zahra Sadeghi et al. This is an open access article distributed under the Creative Commons Attribution License, which permits unrestricted use, distribution, and reproduction in any medium, provided the original work is properly cited.

\begin{abstract}
Supply chains suffer from serious vulnerabilities and disruptions with increasing global crises, including pandemics and natural disasters. Dynamic and complex supply chain environments have constantly led companies to modern management approaches such as resilience to address disruptions. Besides, the sustainability approach enhances the strength of the supply chain in disruptions by considering economic, social, and environmental aspects. This paper develops a mathematical model for designing a supply chain network considering resilience and sustainability. In this model, suppliers were exposed to disruption with different probabilities. The model has three objectives: minimizing total costs and maximizing suppliers' social and environmental scores. A robust scenario-based stochastic programming approach has been used for potential disruption scenarios. The multiobjective model is solved by the $\varepsilon$-constraint method in GAMS software. The numerical results show the performance of the model in a different situation. Also, the robust scenario-based stochastic programming approach allows the average performance of the supply chain in each objective to improve.
\end{abstract}

\section{Introduction}

In the new age, the expansion of information and communication technologies and a decrease in geographic borders' effect caused the development of complicated supply chains. Supply chains, especially in large industries, are installed in different geographical places. They are driven to complicated strategies and processes such as global outsourcing, just-in-time, and lean activities to provide higher quality end products at the proper time and the lowest possible price to customers who are scattered everywhere. Hence, it is needed to create a smooth and uninterrupted flow of materials and information throughout the supply chain. Although these measures lead to lower operating costs, higher product quality, and upgraded commerce agility for the supply chains, companies face various risks by making and implementing these decisions [1]. In general, the globalization of the supply chain and the resulting complexity of the chain structure make them vulnerable to events and disorders such as natural disasters, political instability, strikes, unexpected legal issues, and terrorist acts. Such events, which lead to the disruption of information flow and materials, even if such events are in a remote area, can cause widespread disruptions throughout the supply chain and have many negative effects, called the bullwhip effect [2].

Statistics show a sharp increase in the number of unexpected events and catastrophes that firms have experienced in the recent past. Recent disasters such as tsunami (2004 and 2011), Hurricane Katrina (2005), earthquakes in 1999, 2009, and 2010 in Taiwan, earthquake in Turkey (2012), flood in Thailand (2011), terrorist attacks in New York (2001), Madrid (2004), London (2005), Jakarta (2009), and Mumbai (2008), diseases, and recession show dire consequences, including production downtime, disruption of productivity, and consumed capacity. These issues have unexpected effects on supply chains $[1,3]$. These disruptions have substantial negative consequences on sales returns, 
profit returns, stock returns, brand image, companies' hiring, buyers' safety, and overall supply chain performance [4-6]. COVID-19 is one of the newest events with which the world has been faced. According to the world meter website, most countries will be infected by March 5, 2021. The number of people diagnosed up to that date was 116 million, and the number of reported deaths was 2,570,000 [7].

The pandemic's impact on public health also affects the supply chains' performance, sustainable economic growth, and the environmental performance of supply chains [8]. For example, all 1,000 large companies have been severely affected because all have multiple facilities in quarantined areas [9]. Even before the outbreak was declared a pandemic, production and supply of materials for 938 companies out of 1,000 Fortune companies were severely affected because their 1 st and 2 nd tier suppliers were in Wuhan, China, where the origin is generally believed to be of this disease (Fortune, 2020). Moreover, the severe spread of the virus into Europe and the United States has blocked the movement of products and materials worldwide [10]. Similarly, because of the cessation of operations in some parts of the supply chain, the continuation of supply chain operations has stopped $[11,12]$. While almost all manufacturing firms in various industries have been affected by COVID-19 [9], the effect varies depending on the nature of the products, for example, the impact on high-demand items or low-demand items. In this regard, it can be pointed to the significant increase in demand for some products such as toilet paper, hand detergents and disinfectants, food, and medicine, while demand for some other products such as garments and sports items decreased sharply $[13,14]$. During the pandemic, the impacts on these high-demand items are more immediate and visible, given that these products are essential for daily life and in some cases for survival $[12,15,16]$. Moreover, while firms experience an immediate and sharp increase in demand for these products, they also face a substantial shortage of raw materials during this pandemic $[9,12,17]$. This increase in worldwide demand is a clear example of the consequences of coronavirus disruption.

Supply chains to deal with disturbances, unexpected issues, and reduce risk should be designed to have the ability to face different events and provide an effective response to disruptions. They should have the ability to return to the initial status, or even better condition than before disturbance that is the resilience definition in the supply chains. The resilience of companies assesses their abilities in a fast return to the functional levels before the crisis in the cases such as the production level, the level of services, and the amount of storage [3]. Resilience is the adaptive capability of a supply chain to reduce the probability of sudden disruptions, resist the spread of disturbances, and maintain control over structures and functions. Also, it recovers and responds through immediate and effective reactive plans to transcend the disturbance and restore the supply chain to a robust state of operations. In fact, two concepts of flexibility and redundancy are involved in resilience. For example, having a flexible transport system and flexible production facilities is included in the flexibility, and having multiple suppliers, safety stock, and backup suppliers is a redundancy concept [18].
Various studies have shown that resilience and sustainability are two inspiring approaches in responding to concerns related to living standards in the face of unexpected events. In general, sustainability, on the one hand, according to economic, social, and environmental considerations for both current and future generations, is focused on raising the standard of living. On the other hand, resilience focuses on the response of systems, including economic, social, and environmental systems, to widespread disruptions, persistent external pressure, and systems' ability to return to predisruptive status $[19,20]$. Given the conditions mentioned in today's world, the need to design resilient and sustainable supply chains to deal with natural disasters and contagious diseases is fully felt.

According to the numerous reviewed literature on related research to the sustainable and resilient supply chain, no specific research proposes a robust mathematical model for designing a sustainable and resilient supply chain in four echelons of suppliers, manufacturers, distribution centers, and consumers based on redundancy methods. Hence, this study's main contributions to fill the gap are as follows: (1) development of a robust scenario-based stochastic programming model to design resilient supply portfolios by considering different objectives to achieve sustainable and resilient strategies. The model objectives include minimizing the total cost, minimizing the environmental and social performance scores of suppliers to design a sustainable supply chain, and (2) definition of four strategies for a resilient supply chain based on redundancy practices, which is given as follows.

The first and second strategies have been proposed for suppliers, as the upstream layer of a supply chain plays a vital role in a product's value chain. Pandemics and disasters cause some disruptions in supplying products. When the supplies are disrupted, the whole supply chain becomes vulnerable. Hence, one of the proper strategies to prevent this situation is to have backup suppliers. The second one is to force suppliers to carry the excess capacity of raw materials at a higher cost in the case of any disruption to other suppliers. This strategy helps supply raw materials through suppliers who are less affected by the disruption.

In the third strategy, a certain amount of raw materials is stored as safety stock at the factory before any disruption. The limited capacity of the factory and purchasing price that is less than at disruption time are two main factors for this decision. This strategy enhances the strength of the supply chain to meet demand in any disruption.

In the fourth strategy, in the distribution center, a certain amount of product is stored as a safety stock based on the capacity of the store and its storage cost. As mentioned, some disruptions increase consumers' demand; therefore, this strategy helps answer the growth of needs in the market, such as panic buying.

This article is formatted as follows: the literature review is indicated in Section 2, developing a mathematical model and robust scenario-based programming is indicated in Section 3, the numerical results and sensitivity analysis are explained in Section 4, and the article is concluded in Section 5 . 


\section{Literature Review}

In the last decade, one of the main fields in operations research and mathematical modelling is supply chain design (SCD). SCD helps a company to have a competitive advantage in the market [21]. The companies seek to increase the SC performance that prevents vulnerability [22]. The importance of accessing and sharing supply chain disruption information is essential for the proper deployment of disruption reduction strategies [23]. Because of the importance of this issue and reduction of systems' disruption effects, the authors of [24-26] examined the disruption recovery problems.

Supply chains today are more uncertain than ever. In the face of unforeseen disruptions, sustainability for supply chains is rewarding in terms of competitive advantage. However, the literature is still far from having a sustainable supply chain configuration [27]. Recently, considerable research has been done to simultaneously examine disruptions and the role of sustainability in supply chains that researchers such as Al-Saidi et al. [28], Babbitt et al. [29], Karmaker et al. [30], and Yadav et al. [31] studied these issues when encountered with COVID-19. Gholizadeh et al. [32] developed a sustainable logistic model with four objectives, which include minimizing the total cost, carbon emission coverage for vehicle selection, and the fraud function which gains from the big sharing of supply chain data as well as maximizing demand coverage for vehicle selection simultaneously. Robust fuzzy stochastic programming was used to deal with some uncertainty parameters in this research. They used the augmented $\mathcal{E}$-constraint approach to solve the multiobjective problem.

Infrastructures with reliability and safety are critical to the sustainability of advanced societies. To deal with the increase in destructive events such as man-made and natural disasters that attack infrastructure, resilience must be used as an integrated perspective in the process of system planning [33]. Various resilience strategies have been applied by researchers. Elluru et al. [34] proposed a location-routing problem with time window by considering reactive and proactive scenarios for disaster resilient supply chain. A reactive and proactive approach helps to solve disasters caused by disruption and design of the distribution system, which leads to create a resilient supply chain. Taleizadeh et al. [35] utilized surplus inventory as one of most important resilience strategies in distribution centers in supply chain competition. They proposed a mixed-integer programming model to deal with disruption. Ivanov and Dolgui [36] examined the supply chain resilience for COVID-19 outbreaks. They stated that survival at the level of intertwined supply network requires resilience in each part of the supply chain.

Previous research in this area shows that the theories of sustainability and resilience theory are often studied separately. However, considering the issue of sustainability alongside resilience helps to solve such problems more effectively. One of the first research studies investigating the sustainability-resilience relationship for SCD was conducted by Fahimnia and Jabbarzadeh [19]. In this study, a multiobjective optimization model quantifies the social and environmental performance of the supply chain by using a performance scoring method and a fuzzy goal programming approach was utilized to find trade-off solutions to solve a sustainable-resilient supply chain model. Some researchers studied the design of resilient supply chain network such as Zahiri et al. [37] and developed a multiobjective locationallocation model to design a sustainable-resilient supply chain network under uncertainty. To address the uncertainty, a new fuzzy stochastic-probabilistic programming model was developed. Also, the new measures of sustainability and resilience such as minimizing total cost, maximizing social satisfaction, and minimizing predefined environmental resilience measures were proposed. Jabbarzadeh et al. [1] proposed a hybrid approach to design a sustainable supply chain network. This approach remained sustainable while facing stochastic disruptions in a resilient way. In this article, the C-means fuzzy clustering method was applied to quantify and evaluate suppliers' sustainable performance while facing disruption. Ivanov [38] examined the intersections between sustainability and environmental features in supply chains. This simulation-based research focuses mainly on the analysis of sustainability factors and their role in reducing or increasing the ripple effect in supply chains. This model analyzed the dissemination of disruption in a supply chain by considering sustainability features (economic, social, and environmental aspects) to design a resilient supply chain structure. Souza et al. [39] stated designing a sustainable supply chain that can maximize profit and minimize the environmental effects, but how such policies can influence resilience is not clear. Hence, the ecosystem network analysis approach was proposed to evaluate the resilience when designing the sugar beet supply chain. In this study, a mixed-integer linear programming model was developed to minimize greenhouse gas emissions and maximize profit. Pavlov et al. [40] investigated a gap in research for designing resilient and sustainable supply chain. They presented a model to optimize network redundancy and proactive contingency plans as well. Disruption scenarios led to mitigating supply chain levels. In other words, in each scenario supply chain disruption restructured. In this study, an optimization-simulation method was developed. Table 1 summarizes the studies related to the present study.

Regarding the literature review published in supply chain management, it is perceived that the sustainability and resilience of the supply chain have recently been a heated debate among researchers. According to the literature on sustainable and resilient supply chains, there is no specific research that can propose a robust mathematical model for designing a sustainable and resilient three-echelon supply chain (supplier, manufacturer, and distribution centers) based on redundancy concepts. Accordingly, to cover the existing gap, in this study, an RSSP model is developed for designing resilient portfolios to achieve a sustainable and resilient strategy by considering conflicting goals. In the proposed model, the total cost, suppliers' environmental and social performance scores, and lead time are optimized. The concepts of redundancy-based flexibility and stability are examined in particular. 
TABLE 1: Literature review of sustainability and resilience in supply chain network design.

\begin{tabular}{|c|c|c|c|c|c|c|c|c|c|c|}
\hline \multirow[b]{2}{*}{ Research } & \multirow[b]{2}{*}{ Sustainability } & \multirow[b]{2}{*}{ Resilience } & \multirow[b]{2}{*}{ MODM } & \multicolumn{6}{|c|}{ Solving methods } & \multirow[b]{2}{*}{$\begin{array}{l}\text { Network } \\
\text { redundancy }\end{array}$} \\
\hline & & & & ${ }^{*}$ RFSP & $\begin{array}{l}* * \\
\mathrm{RP}\end{array}$ & $\begin{array}{c}{ }^{* * *} \varepsilon \\
\mathrm{C}\end{array}$ & $\begin{array}{l}\text { Hybrid } \\
\text { approach }\end{array}$ & Simulation & $\begin{array}{l}\text { Scoring } \\
\text { method }\end{array}$ & \\
\hline $\begin{array}{l}\text { Fahimnia and } \\
\text { jabbarzadeh [19] }\end{array}$ & $\checkmark$ & $\checkmark$ & $\checkmark$ & & & & & & $\checkmark$ & \\
\hline Zahiri et al. [37] & $\checkmark$ & $\checkmark$ & $\checkmark$ & $\checkmark$ & & & & & & \\
\hline Jabbarzadeh et al. [1] & $\checkmark$ & $\checkmark$ & & & $\checkmark$ & & $\checkmark$ & $\checkmark$ & & \\
\hline Ivanov [38] & $\checkmark$ & $\checkmark$ & & & & & & $\checkmark$ & & \\
\hline Pavlov et al. [40] & $\checkmark$ & $\checkmark$ & & & & & & & & $\checkmark$ \\
\hline Souza et al. [39] & $\checkmark$ & $\checkmark$ & $\checkmark$ & & & & & & & \\
\hline Elluru et al. [34] & & $\checkmark$ & & & $\checkmark$ & & & & & \\
\hline Gholizadeh et al. [32] & $\checkmark$ & & $\checkmark$ & $\checkmark$ & & $\checkmark$ & & & & \\
\hline Taleizadeh et al. [35] & & $\checkmark$ & & & & & & & & \\
\hline Ivanov and dolgui [41] & & $\checkmark$ & & & & & & & & \\
\hline The research proposal & $\checkmark$ & $\checkmark$ & $\checkmark$ & $\checkmark$ & & & & & $\checkmark$ & $\checkmark$ \\
\hline
\end{tabular}

${ }^{*} \mathrm{RFSP}=$ robust fuzzy stochastic programming; ${ }^{* *} \mathrm{RP}=$ reactive/proactive approach; ${ }^{* * *} \varepsilon C=e$-constraint approach.

The most remarkable innovations in the present paper compared to other research studies done previously are as follows:

(i) Considering a resilient supply portfolio along with designing a sustainable supply chain with economic, social, and environmental considerations

(ii) Proposing a new optimization model to design a sustainable and resilient supply chain considering sustainable objectives in both normal and disrupted conditions

(iii) Proposing four strategies for disruption risk management in a supply chain

(iv) Robust scenario-based programming method for facing disruption scenarios and reducing the decision risks resulted from the model

Accordingly, a multiobjective optimization model is developed for the problem. Different strategies are examined for supply chain resilience and facing disruption risks while providing so that the supply chain performs more effectively under disruption scenarios. Therefore, an RSSP method is applied so as to make the best of these strategies. In the end, for the trade-off between objectives, the LP metric method is used.

\section{Mathematical Model}

In this study, a resilient and sustainable supply chain is designed to deal with pandemics and natural disasters. The supply chain in this paper includes four levels. The first level is suppliers of raw materials, including current and backup suppliers. Although suppliers are independent of the supply chain in this paper, they are evaluated about their environmental and economic performance. The second and third levels are manufacturers and distribution centers that can keep the safety stock of raw material and the final product. The fourth level is customers that trigger the flow of the product in the supply chain by their demand. The model can decide to select suppliers, allocation order, location of capacitated centers, and flow of goods through the supply chain echelons. The information about customers' demand and the place is supposed to be available. Figure 1 indicates a schematic flow of the supply chain.

In this paper, minimizing the total cost is one of the strategic objectives to have a sustainable supply chain, and the model has been completed by adding the maximization of environmental and social scores of the supply chain. In the end, the final solution should be in a way that the supply chain would be resilient under any disruption scenario, and it can keep its performance. Four strategies are defined for a resilient supply chain under disruption scenarios that managers can use a combination of any of these strategies.

The first strategy: have a contract with some of the evaluated and selected suppliers as a backup to provide raw material during disruption.

The second strategy: have a contract with suppliers to use their overcapacity of raw material in any disruption. The price of purchasing the raw material is more than the usual conditions.

The third strategy: storage of raw material as safety stock at manufacturer centers before disruptions. The safety stock has holding costs, and the manufacturer has to make the right decision about the amount of safety stock.

: storage of finished product as safety stock at distribution centers to meet market demand under disruptions. The capacity of the distribution center and holding cost are two effective factors in this decision.

The model has the following assumptions: 


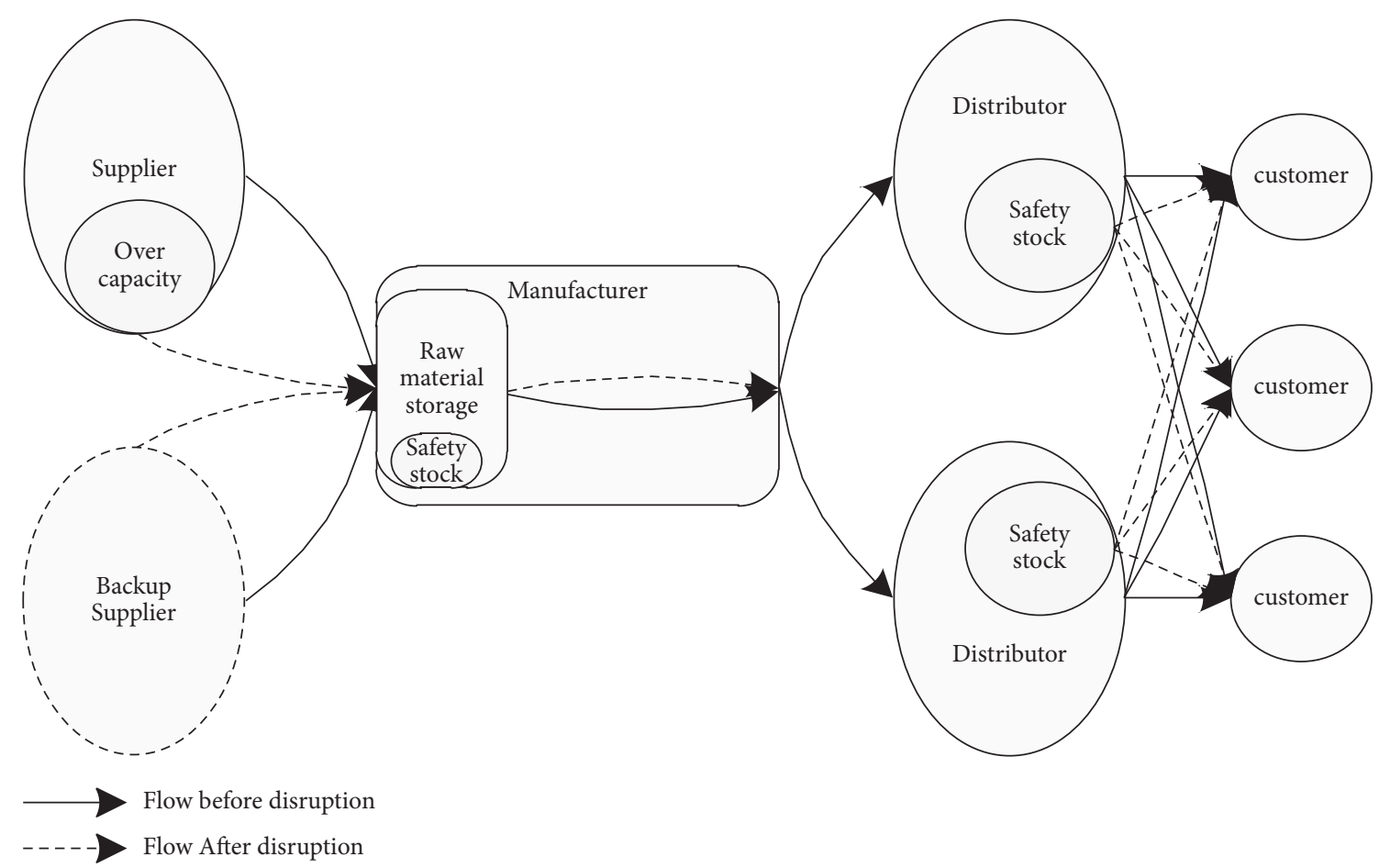

Figure 1: The supply chain network.

(i) The location of the supplier, their capacity, fixed cost of selection, and the purchase cost of raw materials are assumed to be determined

(ii) The backup supplier has been evaluated and selected

(iii) Social and environmental performance scores are already calculated (scores are from 0.1 to 1,1 is for the best performance)

(iv) Potential locations for location of manufacturing centers have been determined

(v) Every factory can produce one or multiple productions with different capacities

(vi) Potential locations for installing distribution centers have been determined

(vii) Raw materials are preservable and not perishable

(viii) Produced goods are preservable and not perishable

(ix) The location and transportation are capacitated

Indices, parameters, and variables of the model are illustrated in Table 2.

Sets and indices:

Set of raw material suppliers: $\mathbf{S}=1,2, \ldots, \mathbf{s}$

Set of raw material backup suppliers: $\mathbf{S} \prime=1,2, \ldots, \mathbf{s}$ '

Set of raw materials: $\mathbf{R}=1,2, \ldots, \mathbf{r}$

Set of products: $\mathbf{P}=1,2, \ldots, \mathbf{p}$

Set of manufacturer: $\mathbf{M}=1,2, \ldots, \mathbf{m}$

Set of distribution centers: $\mathbf{D}=1,2, \ldots, \mathbf{d}$

Set of demand centers, customers, or markets:

$\mathrm{C}=1,2, \ldots, \mathbf{c}$
Set of capacity levels for manufacturers: $\mathbf{A}=1,2, \ldots, \mathbf{a}$ Set of capacity levels for distributing centers: $\mathbf{B}=1,2, \ldots, \mathbf{b}$

Set of probabilistic scenarios of supply disruption: $\mathbf{G}=1,2, \ldots, \mathbf{g}$

Set of disrupted supplier that is subset of suppliers: ds $\subseteq S$

Parameters:

Unit cost of purchasing raw material from supplier $s$ : $\mathrm{pc}_{\mathrm{sr}}$

Unit cost of purchasing raw material $r$ from overcapacity of supplier $s$ under scenario $g$ : $\mathbf{p c g}_{\text {srg }}$

Fixed cost of making contract supplier $s$ for material $r$ : $\mathbf{f c}_{\mathrm{sr}}$ Fixed cost of making contract backup supplier ss for material $r: \mathbf{f c}_{\mathrm{s}, \mathrm{r}}$

Capacity of supplier $s$ for raw material $r$ : cas $_{\text {sr }}$

Social performance score of supplier $s$ for raw material $r: \mathbf{s c s}_{\mathbf{s r}}$

Social performance score of backup supplier $s^{\prime}$ for raw material $r$ : scs ${ }_{s, \mathbf{r}}$

Social performance score of manufacturing center $m$ for product $p: \mathbf{s c m}_{\mathrm{mp}}$

Social performance score of distribution center $d$ for product $p: \mathbf{s c d}_{\mathbf{d p}}$

Environmental performance score of supplier $s$ for raw material $r$ : ens sr $_{\text {s }}$

Environmental performance score of supplier $s^{\prime}$ for raw material $r$ : ens' ${ }_{s, \mathbf{r}}$ 
TABLE 2: Indices, parameters, and decision variables.

Sets and indices

Set of raw material suppliers

Set of raw material backup suppliers

Set of raw materials

Set of products

Set of manufacturer

Set of distribution centers

Set of demand centers, customers, or markets

Set of capacity levels for manufacturers

Set of capacity levels for distributing centers

Set of probabilistic scenarios of supply disruption

Set of disrupted supplier that is subset of suppliers

Parameters

Unit cost of purchasing raw material from supplier $s$

Unit cost of purchasing raw material $r$ from overcapacity of supplier $s$ under scenario $g$

Fixed cost of making contract supplier $s$ for material $r$

Fixed cost of making contract backup supplier $s s$ for material $r$

Capacity of supplier $s$ for raw material $r$

Social performance score of supplier $s$ for raw material $r$

Social performance score of backup supplier $s /$ for raw material $r$

Social performance score of manufacturing center $m$ for product $p$

Social performance score of distribution center $d$ for product $p$

Environmental performance score of supplier $s$ for raw material $r$

Environmental performance score of supplier $s /$ for raw material $r$

Environmental performance score of manufacturing center $m$ for product $p$

Environmental performance score of distribution center $d$ for product $p$

Disruption rate of raw material $r$ for supplier $s$ under scenario $g$

If supplier $s$ can provide raw material $r$, equal 1 , otherwise 0

Amount of raw material $r$ for producing a unit of product $p$

Volume of a unit of raw material $r$

Fixed cost of installing manufacturing center $m$ to produce product $p$ with capacity $a$

Unit cost of producing product $p$ at manufacturing center $m$

Production capacity of manufacturing center $m$ for product $p$ with capacity level $a$

Capacity of manufacturing center $m$ for storage of raw materials $r$

Unit holding cost of raw material $r$ (safety stock)

Fixed cost of installing distribution center $d$ with capacity level $b$

Capacity of distribution $d$ for holding products with capacity level $\mathrm{b}$

Unit holding cost of product $p$ in distributing center $d$ (safety stock)

Unit volume of product $p$

Demand of product $p$ in market $c$

Unit cost of transporting raw material $r$ from supplier $s$ to manufacturer $m$

Unit cost of transporting raw material $r$ from backup supplier $s /$ to manufacturer $m$

Unit cost of transporting product $p$ from manufacturer $m$ to distributing center $d$

Unit cost of transporting product $p$ from distributing center $d$ to customer $c$

Probability of scenario $g$

Flexibility rate of supplier $s$ for raw material $r$ under scenario $g$

Rate of safety stock of raw material $r$ that should be kept hold in manufacturing center $m$

Rate of safety stock of product $d$ that should be kept hold in distributing center $d$

Decision variables

If a supplier $s$ is selected for raw material $r$, equal 1 , otherwise 0

If a backup supplier $s \prime$ is selected for raw material $r$, equal 1 , otherwise 0

If a manufacturing center $m$ with capacity $a$ for product $p$ is installed, equal 1 , otherwise 0

If a distributing center $d$ with capacity $b$ is installed, equal 1 , otherwise 0

Amount of transported raw material $r$ from supplier $s$ to manufacturer $m$ ordered before disruption

Amount of transported product $p$ from manufacturer $m$ to distribution center $d$ before disruption

Amount of transported product $p$ from distribution center $d$ to market $c$ before disruption

Amount of producing product $p$ at manufacturer $m$ before disruption

Amount of safety stock of raw material $r$ at manufacturer $m$

Amount of safety stock of product $p$ in distribution center $d$

Amount of transported raw material $r$ from supplier $s$ to manufacturer $m$ under disruption scenario $g$

Amount of transported raw material $r$ from backup supplier $s$ to manufacturer $m$ under disruption scenario $g$

Amount of transported product $p$ from manufacturer $m$ to distribution center $d$ under disruption scenario $g$

Amount of transported product $p$ transported from distribution center $d$ to market $c$ under disruption scenario $g$

Amount of produced product $p$ at manufacturer $m$ under disruption scenario $g$

Amount of raw material $r$ allocated to supplier $s$

Amount of raw material $r$ allocated to backup suppliers' under disruption scenario $g$

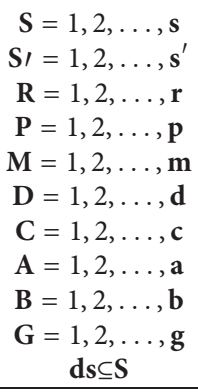

$\mathrm{pc}_{\mathrm{sr}}$

pcg $_{\text {srg }}$

$\mathrm{fc}_{\mathrm{sr}}$

$\mathrm{fc}_{\mathrm{sr}}$

cas $_{\text {sr }}$

$\operatorname{scs}_{\text {sr }}$

$\operatorname{scs}^{\prime} \mathbf{s}^{\prime} \mathbf{r}$

$\mathbf{s c m}_{\mathbf{m p}}$

$\operatorname{scd}_{d p}$

ens $_{\text {sr }}$

ens $^{\prime} s^{\prime} r$

enm $_{m p}$

end $_{d p}$

$\alpha_{\text {srg }}$

$\mathbf{a v}_{\text {sr }}$

$\rho_{\text {rp }}$

$\mathrm{vl}_{\mathbf{r}}$

$\mathrm{fcm}_{\text {mpa }}$

pcm $_{\text {mp }}$

cap $_{\text {mpa }}$

car $_{\text {mr }}$

hcm $_{\mathbf{r}}$

$\operatorname{fcd}_{\mathrm{db}}$

$\operatorname{cad}_{\mathrm{db}}$

$\operatorname{hcd}_{d p}$

$\operatorname{vlp}_{p}$

$\operatorname{dem}_{\mathrm{cp}}$

trs $_{\text {smr }}$

trs $_{\text {s }^{\prime} \mathrm{mr}}$

$\operatorname{trm}_{\mathrm{m} \mathrm{dp}}$

$\operatorname{trd}_{\mathrm{dc} p}$

$p_{g}$

$\mathrm{fl}_{\text {srg }}^{\text {- }}$

rsg $_{d p}$

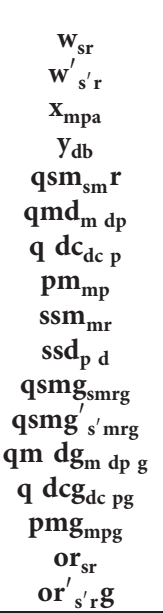


Environmental performance score of manufacturing center $m$ for product $p$ : $\mathbf{e n m}_{\mathbf{m p}}$

Environmental performance score of distribution center $d$ for product $p$ : end $\mathbf{d}_{\mathbf{d p}}$

Disruption rate of raw material $r$ for supplier $s$ under scenario $g: \alpha_{\text {srg }}$

If supplier $s$ can provide raw material $r$, equal 1 , otherwise $0: \mathbf{a v}_{\mathbf{s r}}$

Amount of raw material $r$ for producing a unit of product $p: \rho_{\text {rp }}$

Volume of a unit of raw material $r$ : $\mathbf{v l}_{\mathbf{r}}$

Fixed cost of installing manufacturing center $m$ to produce product $p$ with capacity $a: \mathbf{f c m}_{\text {mpa }}$

Unit cost of producing product $p$ at manufacturing center $m: \mathbf{p c m}_{\mathbf{m p}}$

Production capacity of manufacturing center $m$ for product $p$ with capacity level $a$ : cap mpa

Capacity of manufacturing center $m$ for storage of raw materials $r$ : $\mathbf{c a r}_{\mathbf{m r}}$

Unit holding cost of raw material $r$ (safety stock): $\mathbf{h c m}_{\mathbf{r}}$

Fixed cost of installing distribution center $d$ with capacity level $b$ : $\mathbf{f c d}_{\mathbf{d b}}$

Capacity of distribution $d$ for holding products with capacity level $b$ : cad $_{\mathbf{d b}}$

Unit holding cost of product $p$ in distributing center $d$ (safety stock): hcd $_{\mathbf{d p}}$

Unit volume of product $p: \mathbf{v l p}_{\mathbf{p}}$

Demand of product $p$ in market $c$ : $\mathbf{d e m}_{\mathbf{c p}}$

Unit cost of transporting raw material $r$ from supplier $s$

to manufacturer $m$ : $\operatorname{trs}_{\text {smr }}$

Unit cost of transporting raw material $r$ from backup supplier $s^{\prime}$ to manufacturer $m$ : $\operatorname{trs}_{s_{s}, \mathbf{m r}}$

Unit cost of transporting product $p$ from manufacturer $m$ to distributing center $d$ : $\operatorname{trm}_{\mathbf{m d p}}$

Unit cost of transporting product $p$ from distributing center $d$ to customer $c$ : $\operatorname{trd} \mathbf{d c p}_{\mathrm{dc}}$

Probability of scenario $g: \mathbf{p}_{\mathbf{g}}$

Flexibility rate of supplier $s$ for raw material $r$ under scenario $g$ : $\mathbf{f l}_{\text {srg }}$

Rate of safety stock of raw material $r$ that should be kept hold in manufacturing center $m$ : $\mathbf{r s m}_{\mathbf{m r}}$
Rate of safety stock of product $d$ that should be kept hold in distributing center $d$ : $\mathbf{r s g}_{\mathbf{d p}}$

Decision variables:

If a supplier $s$ is selected for raw material $r$, equal 1 , otherwise $0: \mathbf{w}_{\text {sr }}$

If a backup supplier $s^{\prime}$ is selected for raw material $r$, equal 1 , otherwise $0: \mathbf{w}{ }_{s, \mathbf{r}}$

If a manufacturing center $m$ with capacity $a$ for product $p$ is installed, equal 1, otherwise $0: \mathbf{x}_{\text {mpa }}$

If a distributing center $d$ with capacity $b$ is installed, equal 1, otherwise $0: \mathbf{y}_{\mathbf{d b}}$

Amount of transported raw material $r$ from supplier $s$ to manufacturer $m$ ordered before disruption: $\mathbf{q s m}_{\mathbf{s m}} \mathbf{r}$ Amount of transported product $p$ from manufacturer $m$ to distribution center $d$ before disruption: $\mathbf{q} \mathbf{m d}_{\mathbf{m d p}}$ Amount of transported product $p$ from distribution center $d$ to market $c$ before disruption: $\mathbf{q} \mathbf{d c}_{\mathbf{d c p}}$

Amount of producing product $p$ at manufacturer $m$ before disruption: $\mathbf{p m}_{\mathbf{m p}}$

Amount of safety stock of raw material $r$ at manufacturer $m: \mathbf{s s m}_{\mathrm{mr}}$

Amount of safety stock of product $p$ in distribution center $d$ : $\mathbf{s s d}_{\mathbf{p d}}$

Amount of transported raw material $r$ from supplier $s$ to manufacturer $m$ under disruption scenario $g$ : qsmg $_{\text {smrg }}$

Amount of transported raw material $r$ from backup supplier $s s$ to manufacturer $m$ under disruption scenario $g$ : qsmg ${ }_{s, \mathbf{m r g}}$

Amount of transported product $p$ from manufacturer $m$ to distribution center $d$ under disruption scenario $g$ : qmdg $_{\text {mdpg }}$

Amount of transported product $p$ transported from distribution center $d$ to market $c$ under disruption scenario g: $\mathbf{q d c g}_{\mathrm{dcpg}}$

Amount of produced product $p$ at manufacturer $m$ under disruption scenario $\mathbf{g}$ : $\mathbf{p m g}_{\mathbf{m p g}}$

Amount of raw material $r$ allocated to supplier $s$ : or $_{\text {sr }}$ Amount of raw material $r$ allocated to backup suppliers' under disruption scenario $g$ : or ${ }_{s, \mathbf{r}} \mathbf{g}$

The total cost objective (economic objective) in the normal conditions:

$$
\begin{aligned}
\min Z 1= & \sum_{s} \sum_{r} \mathrm{fc}_{\mathrm{sr}} \cdot w_{s r}+\sum_{s^{\prime}} \sum_{r} \mathrm{fc}_{s^{\prime} r}^{\prime} \cdot w_{s^{\prime} r}^{\prime}+\sum_{m} \sum_{p} \sum_{a} \mathrm{fcm}_{\mathrm{mpa}} \cdot x_{\mathrm{mpa}}+\sum_{d} \sum_{b} \mathrm{fcd}_{\mathrm{db}} \cdot y_{\mathrm{db}} \\
& +\sum_{s} \sum_{m} \sum_{r} \operatorname{trs}_{\mathrm{smr}} \cdot \mathrm{qsm}_{\mathrm{smr}}+\sum_{m} \sum_{d} \sum_{p} \mathrm{trm}_{\mathrm{mdp}} \cdot \mathrm{qmd}_{\mathrm{mdp}}+\sum_{d} \sum_{c} \sum_{p} \operatorname{trd}_{\mathrm{dcp}} \cdot \mathrm{qdc}_{\mathrm{dcp}}+\sum_{s} \sum_{r} \mathrm{pc}_{\mathrm{sr}} \cdot \mathrm{or}_{\mathrm{sr}} \\
& +\sum_{m} \sum_{p} \mathrm{pcm}_{\mathrm{mp}} \cdot \mathrm{pm}_{\mathrm{mp}}+\sum_{m} \sum_{r} \mathrm{hcm}_{r} \cdot \mathrm{ssm}_{\mathrm{mr}}+\sum_{d} \sum_{p} \mathrm{hcd}_{\mathrm{dp}} \cdot \mathrm{ssd}_{\mathrm{dp}} \cdot
\end{aligned}
$$


Costs under disruption scenario $g$ :

$$
\begin{aligned}
& Z 1_{g}=\sum_{s} \sum_{r} \mathrm{pc}_{\mathrm{sr}_{\mathrm{r}}} \cdot \mathrm{os}_{\mathrm{sr}}+\sum_{s} \sum_{r} \mathrm{pcg}_{\mathrm{srg}} \cdot\left(\sum_{m} \mathrm{qsmg}_{\mathrm{smrg}}-\mathrm{or}_{\mathrm{sr}}\right)+\sum_{s^{\prime}} \sum_{r} \mathrm{pcg}_{s^{\prime} \mathrm{rg} \cdot} \cdot \mathrm{or}_{s^{\prime} \mathrm{rg}}^{\prime}+\sum_{s} \sum_{m} \sum_{r} \mathrm{trs}_{\mathrm{smr}} \cdot \mathrm{qsmg}_{\mathrm{smrg}} \\
& +\sum_{s^{\prime}} \sum_{m} \sum_{r} \operatorname{trs}_{s^{\prime} \mathrm{rm}} \cdot \mathrm{qsmg}_{s^{\prime} \mathrm{rmg}}^{\prime}+\sum_{m} \sum_{d} \sum_{p} \operatorname{trm}_{\mathrm{mdp}} \cdot \mathrm{qmdg}_{\mathrm{mdpg}}+\sum \sum \sum \operatorname{trd}_{\mathrm{dcp}} \cdot \mathrm{qdcg}_{\mathrm{dcpg}}+\sum_{m} \sum_{p} \mathrm{pcm} \mathrm{mp} \cdot \mathrm{pmg}_{\mathrm{mpg}} ; \forall g \in G \text {. }
\end{aligned}
$$

Social objective:

$$
\max Z 2=\sum_{s} \sum_{m} \sum_{r} \mathrm{scs}_{\mathrm{sr}} \cdot \mathrm{qsm}_{\mathrm{smr}}+\sum_{m} \sum_{d} \sum_{p} \mathrm{scm}_{\mathrm{mp}} \cdot \mathrm{qmd}_{\mathrm{mdp}}+\sum_{d} \sum_{c} \sum_{p} \mathrm{scd}_{\mathrm{dp}} \cdot \mathrm{qdc}_{\mathrm{dcp}} \cdot
$$

Social objective under disruption scenario $s$ :

$Z 2_{g}=\sum_{s} \sum_{m} \sum_{r} \mathrm{scs}_{\mathrm{sr}} \cdot \mathrm{qsmg}_{\mathrm{smrg}}+\sum_{s^{\prime}} \sum_{m} \sum_{r} \mathrm{scs}_{\mathrm{rs}^{\prime}{ }^{\prime}} \cdot \mathrm{qsmg}_{\mathrm{rs} \mathrm{s}^{\prime} \mathrm{\prime}}+\sum_{m} \sum_{d} \sum_{p} \mathrm{scm}_{\mathrm{mp}} \cdot \mathrm{qmdg}_{\mathrm{mdpg}}+\sum_{d} \sum_{c} \sum_{p} \mathrm{scd}_{\mathrm{dp}} \cdot \mathrm{qdcg}_{\mathrm{dcpg}}, \quad \forall g \in G$.

Environmental objective:

$$
\max Z 3=\sum_{r} \sum_{s} \sum_{m} \mathrm{ens}_{\mathrm{sr}} \cdot \mathrm{qsm}_{\mathrm{rsm}}+\sum_{p} \sum_{m} \sum_{d} \mathrm{enm}_{\mathrm{mp}} \cdot \mathrm{qmd}_{\mathrm{pmd}}+\sum_{p} \sum_{d} \sum_{c} \mathrm{end}_{\mathrm{dc}} \cdot \mathrm{qdc}_{\mathrm{pdc}} \cdot
$$

Environmental objective under disruption scenario $s$ :

$$
Z 3_{g}=\sum_{r} \sum_{s} \sum_{m} \mathrm{ens}_{\mathrm{sr}} \cdot \mathrm{qsmg}_{\mathrm{rsmg}} \sum_{r} \sum_{s^{\prime}} \sum_{m} \mathrm{ens}_{s^{\prime} r} \cdot \mathrm{qsmg}_{\mathrm{rs}{ }^{\prime} \mathrm{mg}}{ }^{\prime}+\sum_{p} \sum_{m} \sum_{d} \mathrm{enm}_{\mathrm{mp}} \cdot \mathrm{qmdg}_{\mathrm{pmdg}}+\sum_{p} \sum_{d} \sum_{c} \mathrm{end}_{\mathrm{dp}} \cdot \mathrm{qdcg}_{\mathrm{pdcg}}, \quad \forall g \in G .
$$

In equation (1), total cost minimization as the economic objective of the resilient-sustainable supply chain design problem is considered before the disruption. The total costs consist of five main terms. First is the cost of facility establishment, including factory and distribution center, as well as supplier and backup supplier selection cost. The second term is the cost of transportation throughout supply chain networks. The third term relates to the cost of purchasing raw material. Fourth is the cost of production, and finally, the fifth term is the holding cost of safety stock of raw materials and final products in factories and distribution centers, respectively. In equation (2), the cost of every disruption scenario is formulated, including the raw material purchasing cost from supplier and backup supplier, production cost, and total transportation cost in the supply chain under scenario $g$. This equation is considered in scenario-based stochastic programming. In equation (3), the maximization of the social score of supply chain is defined. In equation (4), this score is calculated for every disruption scenario. In equation (5), the maximization of the environmental score of supply chain is presented. Moreover, the primary raw materials are green (environmental-friendly). Equation (6) calculates the environmental score for every disruption scenario. 
Constraint:

$$
\sum_{m} \mathrm{qsm}_{\mathrm{smr}} \leq \text { or }_{\mathrm{sr}}, \quad \forall, r \in R, s \in S .
$$

Constraint (7) states that the transported raw material to the manufacturer cannot exceed the allocated order to the supplier.

$$
\mathrm{or}_{\mathrm{sr}} \leq \mathrm{cas}_{\mathrm{sr}} \cdot \mathrm{av}_{\mathrm{sr}} \cdot w_{\mathrm{sr}}, \quad \forall, r \in R, s \in S .
$$

Constraint (8) ensures that when a supplier is selected and a contract is made, a factory can order the raw materials, and the total amount of order of raw material to an established supplier cannot exceed the supplier's capacity.

$$
\mathrm{pm}_{\mathrm{mp}} \leq \sum_{a} \mathrm{cap}_{\mathrm{mpa}} \cdot x_{\mathrm{mpa}} \sum_{a}, \quad \forall, m \in M, p \in P .
$$

Constraint (9) shows that the production level of the installed factory does not exceed its capacity.

$$
\sum_{a} \mathbf{x}_{\mathbf{m p a}} \leq 1, \quad \forall m \in M, p \in P .
$$

Constraint (10) represents that there is, at most, a specific capacity for each factory and product.

$$
\sum_{p} \rho_{\mathrm{rp}} \cdot \mathrm{pm}_{\mathrm{mp}}+\mathrm{ssm}_{\mathrm{mr}}=\sum_{s} \mathrm{qsm}_{\mathrm{smr}}, \quad \forall . r \in R, m \in M .
$$

Constraint (11) indicates the need for raw materials for production and safety stock provided by suppliers.

$$
\mathrm{ssm}_{\mathrm{mr}} \geq \mathrm{rsm}_{\mathrm{mr}} \cdot \sum_{p} \rho_{\mathrm{rp}} \cdot \mathrm{pm}_{\mathrm{mp}}, \quad \forall, r \in R, m \in M .
$$

Constraint (12) shows the minimal amount of raw material as safety stock in the manufacturing center.

$$
\sum_{s^{\prime}} W_{s^{\prime} r}^{\prime} \geq 1, \quad \forall r \in R .
$$

Constraint (13) guarantees that the company contracts with at least a backup supplier before the disruption.

$$
\mathrm{vl}_{r} . \mathrm{ssm}_{\mathrm{mr}} \leq \operatorname{car}_{\mathrm{mr}} . x_{\mathrm{mpa}}, \quad \forall, m \in M, r \in R, p \in P, a \in A \text {. }
$$

Constraint (14) controls the capacity limitation of factories for the safety stock of raw materials.

$$
\mathrm{pm}_{\mathrm{mp}}=\sum_{d} \mathrm{qmd}_{\mathrm{mdp}}, \quad \forall m \in M, p \in P .
$$

Constraint (15) guarantees the balance between the production amount and the output flow in every factory.

$$
\sum_{m} \sum_{p} \operatorname{vlp}_{p} \cdot \mathrm{qmd}_{\mathrm{pmd}} \leq \sum_{b} \mathrm{cad}_{\mathrm{db}} \cdot y_{\mathrm{db}}, \quad \forall, d \in D .
$$

Constraint (16) ensures that transporting products from a factory to a distribution center is possible when locating a distribution center. Moreover, the maximum amount of products that can be transferred cannot be exceeding than the capacity of distributing centers.

$$
\sum_{b} y_{d b} \leq 1, \quad \forall, d \in D \text {. }
$$

Constraint (17) indicates that only one distributing center can be established with a certain capacity in a potential location.

$$
\sum_{m} \mathrm{qmd}_{\mathrm{mdp}}-\mathrm{ssd}_{\mathrm{dp}}=\sum_{c} \mathrm{qdc}_{\mathrm{dcp}}, \quad \forall, d \in D, p \in P .
$$

Constraint (18) guarantees the balance between input and output flows in a distributing center.

$$
\operatorname{ssd}_{\mathrm{dp}} \geq \operatorname{rsg}_{\mathrm{dp}} \cdot \sum_{m} \mathrm{qmd}_{\mathrm{mdp}}, \quad \forall, d \in D, p \in P .
$$

Constraint (19) shows that the at least amount of product as safety stock in the distributing center.

$$
\sum_{d} \mathrm{qdc}_{\mathrm{dcp}}=\operatorname{dem}_{\mathrm{cp}}, \quad \forall, c \in C, p \in P
$$

Constraint (20) is to satisfy the market's demand for every product before any disruption.

The abovementioned constraints are for the normal condition without any disruption. Equations related to disruption scenarios are defined as follows to make the supply chain resilient.

$$
\sum_{m} \mathrm{qsmg}_{\mathrm{smrg}} \leq \operatorname{or}_{s r} \cdot\left(1-\alpha_{\mathrm{srg}}\right), \quad \forall, r \in R, s \in \mathrm{sd}, g \in G .
$$

Constraint (21) expresses that orders are reduced based on disruption rate under every disruption scenario for some suppliers.

$$
\sum_{m} \mathrm{qsmg}_{\mathrm{smrg}} \leq \mathrm{or}_{\mathrm{sr}} \cdot\left(1+\mathrm{fl}_{\mathrm{srg}}\right), \quad \forall, r \in R, s \in \frac{S}{\mathrm{sd}}, g \in G .
$$

Constraint (22) shows undisrupted supplier's flexibility to provide the raw material from overcapacity.

$$
\text { or }_{\mathrm{sr}} \cdot\left(1+\mathrm{fl}_{\mathrm{srg}}\right) \leq \mathrm{cas}_{\mathrm{sr}} \cdot \mathrm{av}_{\mathrm{sr}} \cdot w_{\mathrm{sr}}, \quad \forall, r \in R, s \in \frac{S}{\mathrm{sd}} .
$$

Constraints (23) expresses that it is possible to use overcapacity of suppliers that are not disrupted under any disruption scenario, and the total amount of order of raw material cannot exceed the supplier's capacity.

$$
\begin{gathered}
\sum_{m} \mathrm{qsmg}_{s^{\prime} \operatorname{mrg}}{ }^{\prime} \leq \mathrm{or}_{s^{\prime} r}{ }^{\prime}, \quad \forall, r \in R, s^{\prime} \in S^{\prime}, g \in G, \\
\operatorname{or}_{s^{\prime} \mathrm{rg}}^{\prime} \leq \operatorname{cas}_{s^{\prime}{ }^{\prime} \cdot w_{s^{\prime} r}{ }^{\prime}, \quad \forall, r \in R, s \in S .}
\end{gathered}
$$

Constraints (24) and (25) state that the transported raw material to the manufacturer cannot exceed the allocated order to the backup supplier. 


$$
\sum_{p} \rho_{\mathrm{mp}} \cdot \mathrm{pmg}_{\mathrm{mpg}}=\sum_{s} \mathrm{qsmg}_{\mathrm{smrg}}+\sum_{s^{\prime}} \mathrm{qsmg}_{s^{\prime} \mathrm{mrg}}^{\prime}+\mathrm{ssm}_{m r}, \quad \forall, r \in R, m \in M, g \in G .
$$

Constraint (26) explains that raw materials for producing products in a factory are equal to the total raw materials supplied under that disruption scenario by supplier and backup supplier plus safety stock before the disruption scenario.

$$
\operatorname{pmg}_{\mathrm{mpg}} \leq \sum_{a} \operatorname{cap}_{\mathrm{mpa}} \cdot x_{\mathrm{mpa}}, \quad \forall, m \in M, p \in P .
$$

Constraint (27) guarantees that, under any disruption scenario, production level in every factory (if established) does not exceed its capacity.

$$
\mathrm{pmg}_{\mathrm{mpg}}=\sum_{d} \mathrm{qmdg}_{\mathrm{pmdg}}, \quad \forall, m \in M, p \in P, g \in G \text {. }
$$

Constraint (28) determines the balance between the production amount and output flow in every factory under disruption scenarios.

$$
\sum_{m} \sum_{p} \operatorname{vlp}_{p} \cdot \mathrm{qmdg}_{\mathrm{pmdg}} \leq \sum_{b} \mathrm{cad}_{\mathrm{db}} \cdot y_{\mathrm{db}}, \quad \forall, d \in D, g \in G .
$$

Constraint (29) ensures that transporting products from factories to distributing centers requires locating a distributing center under a disruption scenario, and the accomplishment of this process depends on the capacity of the distributing center.

$$
\sum_{m} \mathrm{qmdg}_{\mathrm{pmdg}}+\operatorname{ssd}_{\mathrm{pd}}=\sum_{c} \mathrm{qdcg}_{\mathrm{pdcg}}, \quad \forall, d \in D, p \in P, g \in G .
$$

Constraint (30) shows the balance between inputs and outputs in distribution centers under disruption scenarios.

$$
\sum_{d} \mathrm{qdcg}_{\mathrm{pdcg}}=\operatorname{dem}_{\mathrm{cp}}, \quad \forall, c \in C, p \in P, g \in G .
$$

Constraint (32) explains the necessity of fulfilling market demand under disruption scenarios.

$$
\begin{aligned}
& \mathrm{qsm}_{\mathrm{rsm}}, \mathrm{qmd}_{\mathrm{pmd}}, \mathrm{qdc}_{\mathrm{pdc}}, \mathrm{pm}_{\mathrm{mp}}, \mathrm{ssm}_{\mathrm{mr}}, \mathrm{ssd}_{\mathrm{pd}}, \mathrm{qsmg}_{\mathrm{rsmg}}, \\
& \mathrm{qmdg}_{\mathrm{pmdg}}, \mathrm{qdcg_{ \textrm {pdcg } }}, \mathrm{pmg}_{\mathrm{mpg}}, \mathrm{or}_{\mathrm{sr}} \geq 0 \\
& w_{s r}, x_{\mathrm{mpa}}, y_{\mathrm{db}} \in\{0,1\} .
\end{aligned}
$$

Moreover, finally, (31) determines the decision variables' range.

3.1. Robust Scenario-Based Stochastic Programming. Scenario-based stochastic programming (SSP) is one of the approaches that can be used in stochastic optimization. In this type of problem, there are two kinds of variables. One group of variables is independent of scenarios, and another group is impacted by scenarios [42]. The objective function in SSP is the mean value of the system under entire scenarios [43]. Generally, this approach can be illustrated as follows:

$$
\left\{\begin{array}{l}
\operatorname{Min} E(Z)=\sum_{s \in S} p_{g} \cdot z_{g}, \\
z_{g}=c_{g}^{\top} \cdot x_{g}+d_{g}^{\top} y \forall, g \in G, \\
A_{g} x_{g}+K_{g} y=b_{g}, \quad \forall, g \in G, \\
R y=q, \\
y \in Y, \quad x_{g} \geq 0 .
\end{array}\right.
$$

Here, $z_{g}$ is the amount of objective function under scenario $g \in G$ and $x_{g}$ is a dependent decision variable and $y$ is an independent decision variable to the scenario. Also, $c_{g}, d_{g}, A_{g}, K_{g}$, and $b_{g}$ are dependent and $R$ and $q$ are independent parameters to the scenario and $p_{g}$ is the probability of occurring scenario $g \in G$.

The proposed method in [43] can consider optimality robustness called robust scenario-based stochastic programming (RSSP) as a quadratic model, so Yu and Li [44] linearized the model as follows:

$$
\left\{\begin{array}{l}
\operatorname{Min} \sum_{g \in G} p r_{g} \cdot z_{g}+\lambda \sum_{g \in G} p_{g} \cdot\left(z_{g}-\sum_{g^{\prime} \in G} p_{g^{\prime}} \cdot z_{g^{\prime}}+2 \theta_{g}\right)+\omega \sum_{g \in G} \pi_{g}\left(\xi_{g}^{+}+\xi_{g}^{-}\right), \\
z_{g}-\sum_{g^{\prime} \in G} \pi_{g^{\prime}} \cdot z_{g^{\prime}}+\theta_{g} \geq 0, \quad \forall, g \in G, \\
z_{g}=c_{g}^{\top} \cdot x_{g}+d_{g}^{\top} y, \quad \forall, g \in G, \\
A_{g} x_{g}+K_{g} y=b_{g}+\left(\xi_{g}^{+}-\xi_{g}^{-}\right), \quad \forall, g \in G, \\
R y=q, \\
\xi_{g}^{+}, \xi_{g}^{-}, \theta_{g} \geq 0, \\
x_{g}, y \geq 0
\end{array}\right.
$$


where $\xi_{g}$ is deviation variable in each scenario, $\omega$ is the risk aversion coefficient, and $\lambda$ is the weight of variance of the cost in different scenarios. The amount of $\omega$ in an example can be cost or penalty of shortage in a supply chain.

Constraint (31) is modified to constraint (34) to apply RSSP while facing disruption scenarios for satisfying demand:

$$
\sum_{d} \mathrm{qdcg}_{\mathrm{pdcg}}=\operatorname{dem}_{\mathrm{cp}}+\left(\xi_{\mathrm{cpg}}^{+}-\xi_{\mathrm{cpg}}^{-}\right), \quad \forall, c \in C, p \in P, g \in G .
$$

Supply chain capacity usually reduces under disruption scenarios, so $\xi_{\mathrm{cps}}^{+}=0$ and just the value $\xi_{\mathrm{cps}}^{-} \geq 0$ in the constraint can make flexibility under disruption scenarios satisfying the demands. It is also assumed $\lambda=0$, and just the mean performance of the system is taken into account. Model robustness is functioned with coefficient $\omega>0$.

Three objective functions of the model defined by applying the RSSP approach are illustrated in the following equation:

$$
\left\{\begin{array}{l}
\operatorname{Min} Z_{1}^{\mathrm{RO}}=Z 1+\sum_{g \in G} p_{g} \cdot Z 1_{g}+\omega \sum_{g \in G} \sum_{c} \sum_{p} p_{g} \cdot \xi_{\mathrm{cpg}}^{-}, \\
\operatorname{Max}_{2}^{\mathrm{RO}}=Z 2+\sum_{g \in G} p_{g} \cdot Z 2_{g}, \\
\operatorname{Max}_{3}^{\mathrm{RO}}=Z 3+\sum_{g \in G} p_{g} \cdot Z 3_{g}, \\
\text { s.t. } \\
\text { Eqs } 7-28, \\
\sum_{d} \mathrm{qdcg}_{\mathrm{pdcg}}=\operatorname{dem}_{\mathrm{cp}}+\left(\xi_{\mathrm{cpg}}^{+}-\xi_{\mathrm{cpg}}^{-}\right), \quad \forall, c \in C, p \in P, g \in G, \\
\mathrm{Eq} 30, \\
\xi_{\mathrm{cpg}}^{-} \geq 0, \\
\omega>0 .
\end{array}\right.
$$

3.2. $\varepsilon$-Constraint Method. Multiobjective problems include more than one objective function, chiefly conflicting objectives. As most real-world optimization problems should be modeled in multiobjective problems, this mathematical modelling area has been widely employed for decades. Many methods and approaches have been developed to tackle multiobjective problems [45].

The $\varepsilon$-constraint method is one of the most efficient methods which can be applied in multiobjective problems. Accordingly, one of the objective functions is optimized and other objectives are added to the constraints. The steps of this method are as follows:

(i) The payoff table is calculated for all objectives

(ii) One objective is selected to be optimized, and other objectives are considered as constraints

(iii) The $\varepsilon$ values account for the constrained objective function

(iv) Efficient solutions (Pareto front) to the problem is achieved by the main objective optimization and the epsilon's parametric variation

\begin{tabular}{|c|c|}
\hline Parameter & Amount of parameter \\
\hline cap $_{\text {mpa }}$ & $\mathrm{A} \sim \mathrm{U}(500,900)$ \\
\hline $\mathrm{car}_{\mathrm{mr}}$ & $\mathrm{U}(300,500)$ \\
\hline $\mathbf{h c m}_{\mathrm{r}}$ & $\mathrm{U}(1,3)$ \\
\hline $\mathrm{fcd}_{\mathrm{db}}$ & $\mathrm{U}(5000,7000)$ \\
\hline $\operatorname{cad}_{\mathrm{db}}$ & $\mathrm{B} \sim(500,900)$ \\
\hline $\operatorname{hcd}_{\mathrm{pd}}$ & $\mathrm{U}(2,4)$ \\
\hline vlp & 1 \\
\hline $\operatorname{dem}_{\mathrm{cp}}$ & $\mathrm{U}(200,300)$ \\
\hline $\operatorname{trs}_{\mathrm{rsm}}$ & $\mathrm{U}(1,2)$ \\
\hline $\operatorname{trm}_{\text {pmd }}$ & $\mathrm{U}(1,2)$ \\
\hline $\operatorname{trd}_{\mathrm{pdc}}$ & $\mathrm{U}(1,2)$ \\
\hline $\mathrm{pcm}_{\mathrm{mp}}$ & $\mathrm{U}(2,3)$ \\
\hline $\mathrm{vl}_{\mathrm{r}}$ & 1 \\
\hline $\mathrm{cls}_{\mathrm{cp}}$ & $\mathrm{U}(3,6)$ \\
\hline$\alpha_{\mathrm{rsg}}$ & $\mathrm{U}(0.4,1)$ \\
\hline $\mathrm{pc}_{\mathrm{rs}}$ & $\mathrm{U}(1,2)$ \\
\hline pcg $_{\text {rsg }}$ & $\mathrm{U}(2,4)$ \\
\hline $\mathrm{fc}_{\mathrm{sr}}$ & $\mathrm{U}(50,100)$ \\
\hline $\operatorname{cas}_{\text {sr }}$ & $\mathrm{U}(300,800)$ \\
\hline $\operatorname{scs}_{\text {sr }}$ & $\mathrm{U}(0.6,1)$ \\
\hline ens $_{\text {sr }}$ & $\mathrm{U}(0.6,1)$ \\
\hline $\operatorname{scs}{ }_{s, r}$ & $\mathrm{U}(0.6,1)$ \\
\hline $\mathrm{scm}_{\mathrm{mp}}^{\mathrm{s}, \mathrm{r}}$ & $\mathrm{U}(0.6,1)$ \\
\hline $\operatorname{scd}_{d p}$ & $\mathrm{U}(0.6,1)$ \\
\hline $\mathrm{enm}_{\mathrm{mp}}$ & $\mathrm{U}(0.6,1)$ \\
\hline end $_{d p}$ & $\mathrm{U}(0.6,1)$ \\
\hline$\rho_{\mathbf{m p}}$ & 1 \\
\hline $\mathrm{fcm}_{\mathrm{mpa}}$ & $\mathrm{U}(7000,10000)$ \\
\hline $\mathrm{fl}_{\text {srg }}$ & $\mathrm{U}(0.1,0.5)$ \\
\hline
\end{tabular}

TABLE 3: The amount of input parameters.

(v) Report the Pareto solutions

\section{Numerical Example}

A numerical example under different scenarios has been applied to check feasibility and evaluation of the performance of the model (Table 3). In this example, the supply chain network has four echelons, including suppliers, manufacturers, distributors, and customers. It is assumed that this supply chain has two manufacturers currently with two different capacity levels. There are three distribution centers with two different capacity levels and five demand centers as customers.

It is also assumed that two types of raw materials are needed to produce a product that is provided by four potential suppliers and two backup suppliers. In global disasters and pandemics, suppliers are one of the main parts of a supply chain that is vulnerable; hence, the four various disruption scenarios to prove the performance of the model are shown in Table 4. In this table, for example, the probability of scenario one is 0.75 , and in this scenario, the disruption rate of supplier S1 for material $\mathrm{r} 1$ is 0.6 .

The computations are run on an Intel $^{\otimes}$ Core $^{\mathrm{TM}}$ i5$2.5 \mathrm{GHz}$ processor and $4 \mathrm{~GB}$ of Ram by GAMS 24.0.1 software using Bonmin solver.

In this part, the model is optimized to achieve results before any disruption. Every objective of the problem is optimized solely, and the value of other objectives is 
TABLE 4: Disruption scenarios for suppliers.

\begin{tabular}{|c|c|c|c|c|c|c|c|c|c|c|}
\hline \multirow{3}{*}{ No. of scenario } & \multirow{3}{*}{ Probability of scenario $\left(p_{g}\right)$} & \multirow{3}{*}{ Disrupted suppliers } & \multicolumn{8}{|c|}{$\begin{array}{l}\text { Disruption rate of suppliers }(s) \text { for raw material }(r) \text { under } \\
\text { scenarios }(\mathrm{g})\end{array}$} \\
\hline & & & \multicolumn{2}{|c|}{$S_{1}$} & \multicolumn{2}{|c|}{$S_{2}$} & \multicolumn{2}{|c|}{$S_{3}$} & \multicolumn{2}{|c|}{$S_{4}$} \\
\hline & & & $r_{1}$ & $r_{2}$ & $r_{1}$ & $r_{2}$ & $r_{1}$ & $r_{2}$ & $r_{1}$ & $r_{2}$ \\
\hline 1 & 0.5 & $S 1, S 2$ & 0.6 & & 0.4 & & & & & \\
\hline 2 & 0.3 & $S 1, S 2$ & 1 & 1 & 0.4 & 0.4 & & & & \\
\hline 3 & 0.15 & $S 1, S 2, S 4$ & 0.6 & & 0.6 & & & & 0.5 & 0.5 \\
\hline 4 & 0.05 & $S 1, S 2, S 3, S 4$ & & 0.4 & 0.5 & & 1 & 1 & 0.5 & 0.5 \\
\hline
\end{tabular}

calculated based on the optimized objective to show the trade-off between objectives. For example, first, $Z_{1}$ (economic objective) is minimized, and the value of other objectives are achieved based on the optimized value of $Z_{1}$. Table 4 shows the values of the minimized costs and other objectives' amount such the environmental score before any disruption scenarios. Moreover, the amount of raw material and safety stock of raw material are illustrated in Table 5. Similarly, Tables 6 and 7, respectively, show the optimized value of social score $\left(Z_{2}\right)$ and environmental score $\left(Z_{3}\right)$.

The proposed model is a multiobjective model, so the $\mathcal{E}$-constraint method is used to convert the model to a singleobjective model. Table 8 shows the payoff table of the three mentioned objectives.

To use the propose method, the first objective was optimized and the rest objectives were placed in the constraints by seven different values of $\varepsilon$ to show conflicting of the objective function and reach the Pareto solutions. Table 9 shows Pareto solutions based on seven different $\varepsilon$ values.

Additionally, Figure 2 illustrates a comparison of the values of objective functions $Z_{1}-Z_{2}$ and $Z_{1}-Z_{3}$ as an example to prove the conflict between two objectives.

It is evident from Figure 2 and Table 8 that, to cover the economic priorities as the first objective function, the social and environmental values in the supply chain are decreasing.

\subsection{Results of Robust Scenario-Based Stochastic Programming.}

The outputs of the model in the normal condition are not suitable for disruption because the supply chain can lose its performance. Therefore, using the robust scenario-based stochastic programming approach helps to consider a summation of before and after disruption condition together. In the solved example, amount of $\omega=1$. The value of each objective in this approach is shown in Table 10 .

The results show that amount of total cost in this method increases in comparison to the normal condition. All suppliers are involved in providing the raw material and also the selected backup suppliers to deal with disruption. Hence, it is necessary to have sensitivity analysis on model robustness parameter $(\omega)$ before applying this method. For this reason, the effect of three different values of $(\omega)$ on objective function $\left(Z_{1}^{\mathrm{RO}}\right)$ and deviation variable from demand $\left(\xi_{\mathrm{cpg}}^{-}\right)$ is shown in Table 11.
Table 9 shows the changes in the total cost and the amount of unfulfilled demand (the shortage due to supply disruption) relative to changes in $(\omega)$. The amount of $(\omega)$ can be considered as a penalty of shortage in the supply chain. It is clear that amount of unfulfilled demand is decreasing by increasing the amount of penalty $(\omega)$. The model is completely robust with $\omega \geq 15$, and the amount of shortage equals 0 . Figure 3 can prove that the model is entirely risk-averse when the total cost gets the maximum value, over 64621. Despite reducing the total cost, the total unfulfilled demand for two products increases significantly, and model robustness is intensely mitigated with $<15$.

By comparing, the results in Tables 5, 10, and 11 demonstrate that the supply chain has the lowest cost in the normal condition. So, if some disruptions happen, the supply chain is not prepared to meet the demands in the market. On the other hand, the total cost increases when the supply chain considers the disruption scenarios and is responsive to the demand. Hence, regarding the current situation in the world that pandemics and disasters impose a high cost on industries and supply chains, putting more investment into a resilient and sustainable supply chain is reasonable. The resilient and sustainable supply chain can mitigate risk and increase the responsiveness of SC in the future of the world.

By implementing the model on a numerical study, the numerical results show that the proposed model and approaches have the ability to solve the problem of sustainableresilient supply chain design. Based on the numerical results on a hypothetical supply chain under normal conditions, if only the economic objective is considered, the minimum cost for the supply chain occurs, while the answer is debatable in two ways. First, other objectives may not be placed in good conditions, and social and environmental performance scores may be low in the supply chain; second, in any supply disruption scenario, supply chain performance is severely disrupted, and high costs, including shortages and nonsupply, occur. In other words, the answer is only economical, neither sustainable nor resilient. Similarly, the answer can only be optimal in normal conditions from an environmental or social perspective, while other objectives are not optimal, and the answer is not resilient. Also, supplier disruptions are shown with several possible scenarios to show different situations in the real world. In each 
TABLE 5: Value of objective functions and supply portfolio by optimizing $Z_{1}$.

\begin{tabular}{|c|c|c|c|}
\hline & $\begin{array}{c}\text { Environmental score } \\
4050\end{array}$ & $\begin{array}{c}\text { Social score } \\
4246\end{array}$ & $\begin{array}{c}\text { Optimized value of } Z_{1} \\
55990\end{array}$ \\
\hline Amount of raw material 1 & & Amount of raw material 1 & Supplier \\
\hline 500 & & 300 & S1 \\
\hline 173 & & 500 & $\mathrm{~S} 2$ \\
\hline 450 & & 373 & S3 \\
\hline 450 & & 400 & S4 \\
\hline Amount of SS raw material 2 & & Amount of SS raw material 1 & Manufacturer \\
\hline 11 & & 38 & M1 \\
\hline 57 & & 23 & M2 \\
\hline
\end{tabular}

TABle 6: Value of objective functions and supply portfolio by optimizing $Z_{2}$.

\begin{tabular}{|c|c|c|c|}
\hline & $\begin{array}{c}\text { Environmental score } \\
4095 \\
\end{array}$ & $\begin{array}{l}\text { Optimized value of social score }\left(Z_{2}\right) \\
4527\end{array}$ & $\begin{array}{c}\text { Economic score } \\
75350 \\
\end{array}$ \\
\hline Amount of raw material 2 & & Amount of raw material 1 & Supplier \\
\hline 300 & & 500 & S1 \\
\hline 500 & & 500 & $\mathrm{~S} 2$ \\
\hline 400 & & 450 & S3 \\
\hline 400 & & 450 & S4 \\
\hline Amount of SS raw material 2 & & Amount of SS raw material 1 & Manufacturer \\
\hline 27 & & 62 & M1 \\
\hline 63 & & 0 & M2 \\
\hline
\end{tabular}

TABLE 7: Value of objective functions and supply portfolio by optimizing $Z_{3}$.

\begin{tabular}{|c|c|c|c|}
\hline & $\begin{array}{l}\text { Optimized value of environmental score }\left(Z_{3}\right) \\
439\end{array}$ & $\begin{array}{l}\text { Social score } \\
4359\end{array}$ & $\begin{array}{l}\text { Economic score } \\
76873\end{array}$ \\
\hline Amount of raw material 2 & & Amount of raw material 1 & Supplier \\
\hline 300 & & 500 & S1 \\
\hline 500 & & 500 & $\mathrm{~S} 2$ \\
\hline 400 & & 450 & S3 \\
\hline 400 & & 450 & S4 \\
\hline Amount of SS raw material 2 & & Amount of SS raw material 1 & Manufacturer \\
\hline 18 & & 86 & M1 \\
\hline 180 & & 18 & M2 \\
\hline
\end{tabular}

TABLe 8: Payoff table of three objectives.

\begin{tabular}{lccc}
\hline Objective & $Z_{1}$ & $Z_{2}$ & $Z_{3}$ \\
\hline$Z_{1}$ & 55990 & 75350 & 76873 \\
$Z_{2}$ & 4246 & 4527 & 4359 \\
$Z_{3}$ & 4050 & 4095 & 4391 \\
\hline
\end{tabular}

TABle 9: Pareto solutions of objective functions.

\begin{tabular}{lccccccc}
\hline Objective function & $\varepsilon 0$ & $\varepsilon 1$ & $\varepsilon 2$ & $\varepsilon 3$ & $\varepsilon 4$ & $\varepsilon 5$ & 56 \\
\hline$Z_{1}$ & 56283 & 56440 & 56623 & 56806 & 56988 & 57173 & 57420 \\
$Z_{2}$ & 4359 & 4375 & 4392 & 4409 & 4426 & 4443 \\
$Z_{3}$ & 4095 & 4124 & 4154 & 4183 & 4213 & 4243 \\
\hline
\end{tabular}



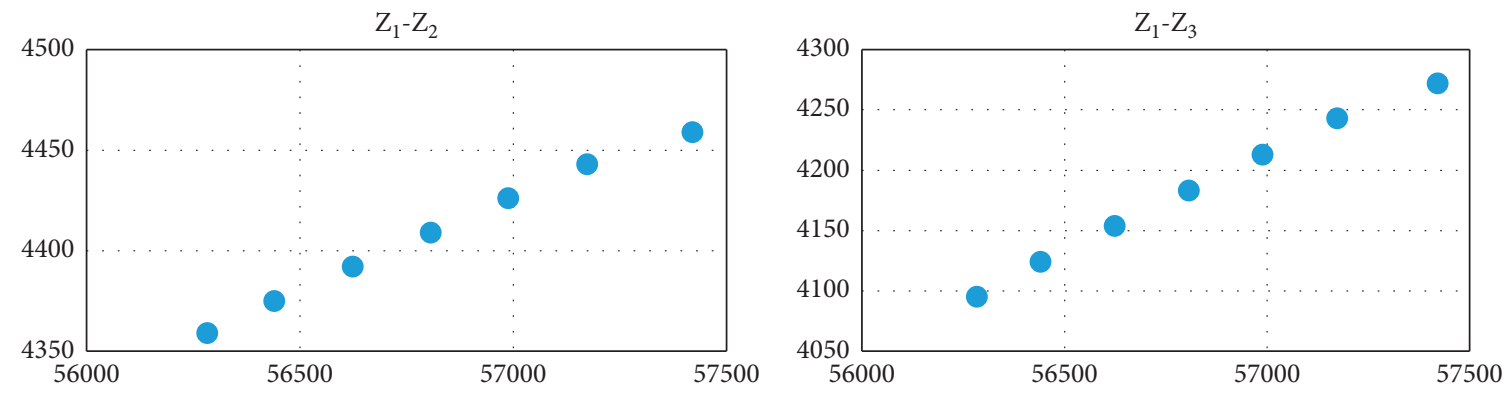

Figure 2: Pareto solutions of $Z_{1}-Z_{2}$ and $Z_{1}-Z_{3}$.

TABLE 10: Value of objective functions and supply portfolio using the SSP approach.

\begin{tabular}{|c|c|c|c|}
\hline $\begin{array}{l}\text { Mean of environmental score } \\
\text { under normal and disruption } \\
Z_{3}^{\mathrm{RO}}\end{array}$ & $\begin{array}{l}\text { Mean of social score under normal and disruption } \\
\qquad Z_{2}^{\mathrm{RO}}\end{array}$ & & $\begin{array}{l}\text { Mean of economic score under normal } \\
\text { and disruption } Z_{1}^{\mathrm{RO}}\end{array}$ \\
\hline 6603 & 7076 & & 56671 \\
\hline $\begin{array}{l}\text { Amount of raw material } \\
2\end{array}$ & Amount of raw material 1 & & Supplier \\
\hline 535 & 357 & $g_{1}$ & S1 \\
\hline 492 & 357 & $g_{2}$ & S2 \\
\hline 44 & 323 & $g_{3}$ & S3 \\
\hline 500 & 535 & $g_{4}$ & S4 \\
\hline $\begin{array}{l}\text { Amount of raw material } \\
2\end{array}$ & Amount of raw material 1 & $g_{1}$ & Backup supplier \\
\hline 500 & 0 & $g_{2}$ & $S_{1}^{\prime}$ \\
\hline 500 & 0 & $g_{3}$ & \\
\hline 463 & 0 & $g_{4}$ & \\
\hline 367 & 0 & Scenario & \\
\hline 0 & 500 & $g_{1}$ & $S_{2}^{\prime}$ \\
\hline 0 & 500 & $g_{2}$ & \\
\hline 0 & 463 & $g_{3}$ & \\
\hline 0 & 191 & $g_{4}$ & \\
\hline
\end{tabular}

TABLE 11: Effect of different amounts of $(\omega)$ on objective function and deviation of demand.

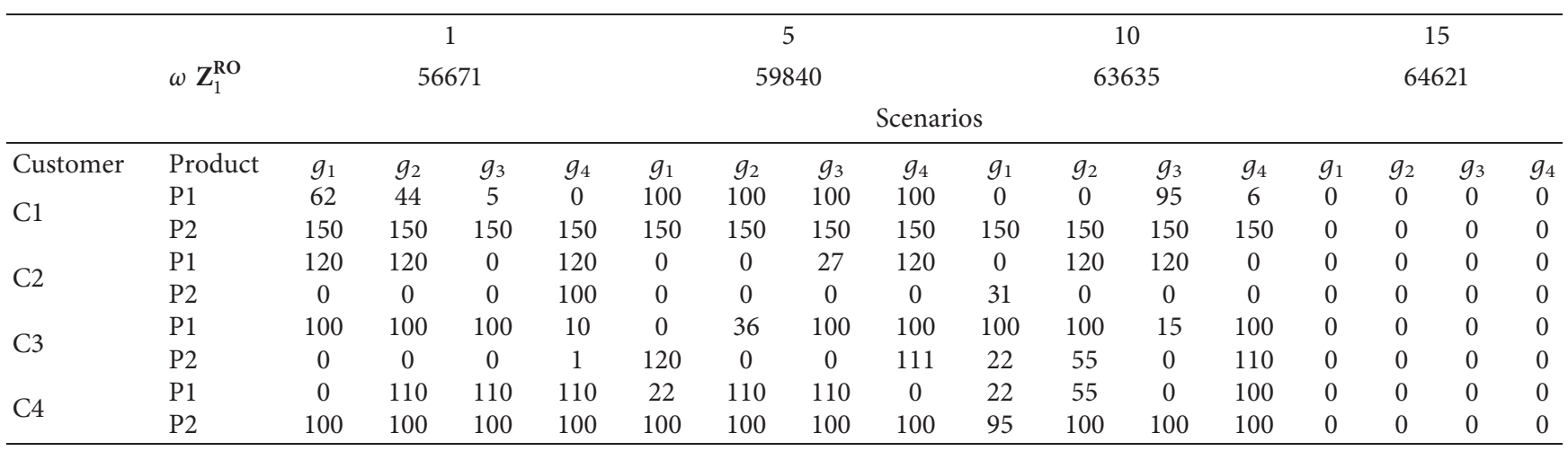




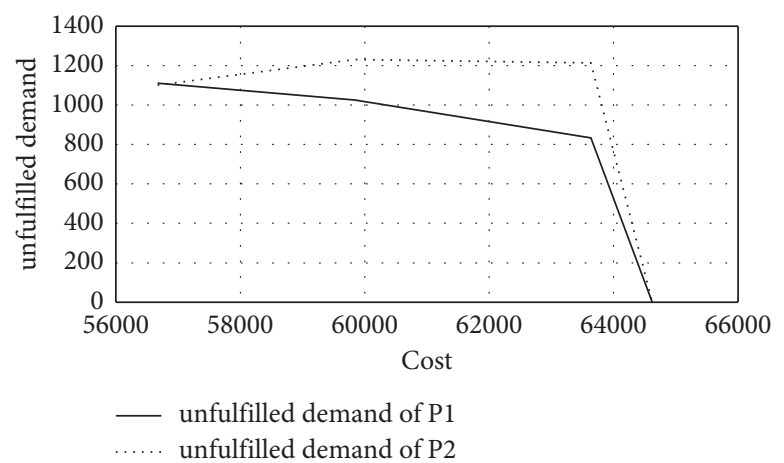

Figure 3: Trade-off between total cost, unfulfilled demand, and $(\omega)$.

scenario, it is determined which suppliers and how much of their supply capacity are lost. Then, considering disruption scenarios for suppliers as well as their social and environmental performance, the resilient-sustainable supply chain using the RSSP approach has been achieved.

\section{Conclusion}

In this paper, a multiobjective model for a sustainable and resilient supply chain network is formulated to deal with disruptions in disasters. The model optimizes a sustainableresilient supply chain. The main objective of this model is to minimize supply chain costs, which is considered along with sustainable objectives that include maximizing social and environmental scores. In this regard, four strategies are proposed for a resilient supply chain based on redundancy practices. In this context, an RSSP method is applied to make the best of these strategies.

The $\mathcal{E}$-constraint method with different values of $\varepsilon$ is utilized to convert the multiobjective model to the singleobjective model, and it is solved by GAMS software. The performance of the model is evaluated by considering normal and disrupted conditions using a numerical example. Given the output of the numerical example and considering only the total cost objective, the minimum cost of the supply chain results in normal conditions. This solution is only economical and neither sustainable nor resilient. Therefore, under the supply disruption scenario, the supply chain performance is severely disrupted and many costs may be imposed, lack of supply. The model proves that the amount of cost objective increases when the disruption condition considers the objective function. However, it can be concluded that the supply chain has the lowest cost in the normal condition and the supply chain cannot tolerate any vulnerability. On the other hand, the sustainable and resilient supply chain can mitigate risk and take disruption by more investment.

One aspect that could be considered in future research is using a real case study instead of random numbers. The proposed model is NP-hard model; new metaheuristic algorithms are also proposed to solve this problem on larger scales. Finally, in disaster situations, most of the parameters are uncertain; using fuzzy number helps to improve the model.

\section{Data Availability}

The data used to support the findings of this study are available from the corresponding author upon request.

\section{Conflicts of Interest}

The authors declare that they have no conflicts of interest.

\section{References}

[1] A. Jabbarzadeh, B. Fahimnia, and F. Sabouhi, "Resilient and sustainable supply chain design: sustainability analysis under disruption risks," International Journal of Production Research, vol. 56, no. 17, pp. 5945-5968, 2018.

[2] M. Christopher and H. Peck, "Building the resilient supply chain," 2004.

[3] S. Rezapour, R. Z. Farahani, and M. Pourakbar, "Resilient supply chain network design under competition: a case study," European Journal of Operational Research, vol. 259, no. 3, pp. 1017-1035, 2017.

[4] K. B. Hendricks and V. R. Singhal, "The effect of supply chain glitches on shareholder wealth," Journal of Operations Management, vol. 21, no. 5, pp. 501-522, 2003.

[5] J.-H. Thun and D. Hoenig, "An empirical analysis of supply chain risk management in the German automotive industry," International Journal of Production Economics, vol. 131, no. 1, pp. 242-249, 2011.

[6] G. A. Zsidisin, "A grounded definition of supply risk," Journal of Purchasing and Supply Management, vol. 9, no. 5-6, pp. 217-224, 2003.

[7] https://www.nationalgeographic.com/history/reference/mo dern-history/why-we-evolved-to-feel-panic-anxiety/.

[8] M. A. Moktadir, A. Dwivedi, A. Rahman et al., "An investigation of key performance indicators for operational excellence towards sustainability in the leather products industry," Business Strategy and the Environment, vol. 29, no. 8, pp. 3331-3351, 2020.

[9] T. Linton and B. Vakil, "Coronavirus is proving we need more resilient supply chains," Harward business review, March, vol. 5, p. 2020, 2020.

[10] P.-I. Lee, Y.-L. Hu, P.-Y. Chen, Y.-C. Huang, and P.-R. Hsueh, "Are children less susceptible to COVID-19?" Journal of Microbiology, Immunology, and Infection, vol. 53, no. 3, pp. 371-372, 2020.

[11] L. Breen and C. Hannibal, "Learning from the Covid-19 pandemic: planning, controlling and driving change for greater resilience in supply chains: special issue call for 
papers," Supply Chain Management: International Journal, vol. 17, 2020.

[12] D. Ivanov, "Viable supply chain model: integrating agility, resilience and sustainability perspectives-lessons from and thinking beyond the COVID-19 pandemic," Annals of Operations Research, vol. 33, pp. 1-21, 2020.

[13] E. Bagshaw and D. Powell, Supermarkets Stockpile, Toilet Paper Production Runs 24 Hours, The Sydney Morning Herald, New South Wales, Australia, 2020.

[14] P. Haren and D. Simchi-Levi, "How coronavirus could impact the global supply chain by mid-March," Harvard Business Review, vol. 28, 2020.

[15] T. K. Dasaklis, C. P. Pappis, and N. P. Rachaniotis, "Epidemics control and logistics operations: a review," International Journal of Production Economics, vol. 139, no. 2, pp. 393-410, 2012.

[16] M. Koyuncu and R. Erol, "Optimal resource allocation model to mitigate the impact of pandemic influenza: a case study for Turkey," Journal of Medical Systems, vol. 34, no. 1, pp. 61-70, 2010.

[17] L. M. Koonin, "Novel coronavirus disease (COVID-19) outbreak: now is the time to refresh pandemic plans," Journal of Business Continuity \& Emergency Planning, vol. 13, no. 4, pp. 1-15, 2020.

[18] M. Kamalahmadi and M. M. Parast, "A review of the literature on the principles of enterprise and supply chain resilience: major findings and directions for future research," International Journal of Production Economics, vol. 171, pp. 116-133, 2016.

[19] B. Fahimnia and A. Jabbarzadeh, "Marrying supply chain sustainability and resilience: a match made in heaven," Transportation Research Part E: Logistics and Transportation Review, vol. 91, pp. 306-324, 2016.

[20] D. Marchese, E. Reynolds, M. E. Bates, H. Morgan, S. S. Clark, and I. Linkov, "Resilience and sustainability: similarities and differences in environmental management applications," The Science of the Total Environment, vol. 613, pp. 1275-1283, 2018.

[21] Z. Azarmand and E. Neishabouri, Location Allocation Problem, Facility Location, Springer, Heidelberg, Germany, 2009.

[22] L. V. Snyder, Z. Atan, P. Peng, Y. Rong, A. J. Schmitt, and B. Sinsoysal, "OR/MS models for supply chain disruptions: a review," IIE Transactions (Institute of Industrial Engineers), vol. 48, no. 2, pp. 89-109, 2016.

[23] A. V. Thomas and B. Mahanty, "Dynamic assessment of control system designs of information shared supply chain network experiencing supplier disruption," Operational Research, vol. 27, 2018.

[24] R. Aldrighetti, D. Battini, D. Ivanov, and I. Zennaro, "Costs of resilience and disruptions in supply chain network design models: a review and future research directions," International Journal of Production Economics, vol. 24, Article ID 108103, 2021.

[25] M. S. Golan, B. D. Trump, J. C. Cegan, and I. Linkov, "Supply chain resilience for vaccines: review of modeling approaches in the context of the COVID-19 pandemic," Industrial Management \& Data Systems, vol. 43, 2021.

[26] B. Scala and C. F. Lindsay, "Supply chain resilience during pandemic disruption: evidence from healthcare," Supply Chain Management: International Journal, vol. 26, 2021.

[27] A. Durmaz, H. Demir, and B. Sezen, "The role of negative entropy within supply chain sustainability," Sustainable Production and Consumption, vol. 34, 2021.
[28] M. Al-Saidi and H. Hussein, "The water-energy-food nexus and COVID-19: towards a systematization of impacts and responses," The Science of the Total Environment, vol. 779, Article ID 146529, 2021.

[29] C. W. Babbitt, G. A. Babbitt, and J. Oehman, "Behavioral impacts on residential food provisioning, use, and waste during the COVID-19 pandemic," Sustainable Production and Consumption, vol. 28, 2021.

[30] C. L. Karmaker, T. Ahmed, S. Ahmed, S. M. Ali, M. A. Moktadir, and G. Kabir, "Improving supply chain sustainability in the context of COVID-19 pandemic in an emerging economy: exploring drivers using an integrated model," Sustainable production and consumption, vol. 26, pp. 411-427, 2021.

[31] S. Yadav, S. Luthra, and D. Garg, "Modelling Internet of things (IoT)-driven global sustainability in multi-tier agrifood supply chain under natural epidemic outbreaks," Environmental Science and Pollution Research, vol. 28, no. 13, pp. 16633-16654, 2021.

[32] H. Gholizadeh, H. Fazlollahtabar, and M. Khalilzadeh, "A robust fuzzy stochastic programming for sustainable procurement and logistics under hybrid uncertainty using big data," Journal of Cleaner Production, vol. 258, Article ID 120640, 2020.

[33] Y. P. Fang, C. Fang, E. Zio, and M. Xie, "Resilient critical infrastructure planning under disruptions considering recovery scheduling," IEEE Transactions on Engineering Management, vol. 26, 2019.

[34] S. Elluru, H. Gupta, H. Kaur, and S. P. Singh, "Proactive and reactive models for disaster resilient supply chain," Annals of Operations Research, vol. 283, no. 1-2, pp. 199-224, 2019.

[35] A. A. Taleizadeh, A. Ghavamifar, and A. Khosrojerdi, Resilient Network Design of Two Supply Chains under Price Competition: Game Theoretic and Decomposition Algorithm Approach, Springer, Berlin, Germany, 2020.

[36] D. Ivanov, "Predicting the impacts of epidemic outbreaks on global supply chains: a simulation-based analysis on the coronavirus outbreak (COVID-19/SARS-CoV-2) case," Transportation Research Part E: Logistics and Transportation Review, vol. 136, Article ID 101922, 2020.

[37] B. Zahiri, J. Zhuang, and M. Mohammadi, "Toward an integrated sustainable-resilient supply chain: a pharmaceutical case study," Transportation Research Part E: Logistics and Transportation Review, vol. 103, pp. 109-142, 2017.

[38] D. Ivanov, "Revealing interfaces of supply chain resilience and sustainability: a simulation study," International Journal of Production Research, vol. 56, no. 10, pp. 3507-3523, 2018.

[39] V. D. Souza, J. Bloemhof-Ruwaard, and M. Borsato, "Exploring ecosystem network analysis to balance resilience and performance in sustainable supply chain design," International Journal of Advanced Operations Management, vol. 11, no. 1-2, pp. 26-45, 2019.

[40] A. Pavlov, D. Ivanov, D. Pavlov, and A. Slinko, "Optimization of network redundancy and contingency planning in sustainable and resilient supply chain resource management under conditions of structural dynamics," Annals of Operations Research, vol. 27, pp. 1-30, 2019.

[41] D. Ivanov and A. Dolgui, "Viability of intertwined supply networks: extending the supply chain resilience angles towards survivability. A position paper motivated by COVID19 outbreak," International Journal of Production Research, vol. 58, no. 10, pp. 2904-2915, 2020.

[42] E.-H. Aghezzaf, C. Sitompul, and N. M. Najid, "Models for robust tactical planning in multi-stage production systems 
with uncertain demands," Computers \& Operations Research, vol. 37, no. 5, pp. 880-889, 2010.

[43] J. M. Mulvey, R. J. Vanderbei, and S. A. Zenios, "Robust optimization of large-scale systems," Operations Research, vol. 43 , no. 2, pp. 264-281, 1995.

[44] C.-S. Yu and H.-L. Li, "A robust optimization model for stochastic logistic problems," International Journal of Production Economics, vol. 64, no. 1-3, pp. 385-397, 2000.

[45] K. Deb and K. Deb, "Multi-objective optimization," Search Methodologies, Springer, Boston, MA, USA, pp. 403-449, 2014. 